\title{
Surface Water Potential Assessment and Water Demand Evaluation (A Case of Dabus Watershed, Blue Nile Basin)
}

\author{
Bilal Kemal $^{1}$, Dereje Adeba ${ }^{2}$ \\ ${ }^{1}$ Water Resources and Irrigation Engineering, Engineering College, Asosa University, Asosa, Ethiopia \\ ${ }^{2}$ Hydraulic and Water Resources Engineering, Engineering College, Wollega University, Nekemte, Ethiopia \\ Email: Anbesawbilal@gmail.com,mo_derejeadeba2018@yahoo.com
}

How to cite this paper: Bilal, K. and Dereje, A. (2021) Surface Water Potential Assessment and Water Demand Evaluation (A Case of Dabus Watershed, Blue Nile Basin). Computational Water, Energy, and Environmental Engineering, 10, 155-168. https://doi.org/10.4236/cweee.2021.104012

Received: June 8, 2021

Accepted: August 20, 2021

Published: August 23, 2021

Copyright $\odot 2021$ by author(s) and Scientific Research Publishing Inc. This work is licensed under the Creative Commons Attribution International License (CC BY 4.0).

http://creativecommons.org/licenses/by/4.0/

\begin{abstract}
Dabus sub-basin is one of the main tributaries of Blue Nile with a considerable surface water potential which can be used for hydro power, irrigation, and water supply. Lack of studies regarding surface water potential and demands at the sub-basin level is the reason why this potential was underutilized. The objective of this study is to assess the surface water potential and evaluate the current and future demand by using Water Evaluation and Planning (WEAP) model at Dabus sub-basin. The model was constructed on four different scenarios starting from the current account (2020) wherein all the data is filled into the model to estimate the surface water potential and demands for different sectors. The scenarios include Scenario 1: reference scenario; Scenario 2: Change in population growth rate; Scenario 3: Irrigation water demand projection; and Scenario 4: Increased domestic water demand. The scenario has helped in analyzing "what if" questions. For all the scenarios the overall demand, coverage and unmet demand were analyzed based on three-time horizon as (2020-2030, 2030-2040, and 2040-2050). The model estimated the average annual flow as 6.536 Billion Cubic Meter (BCM) which is generated from annual precipitation of 14.987 BCM. The model showed $100 \%$ demand coverage for all the scenarios except the irrigation demand projection scenario which have unmet demand on some of the months of the year.
\end{abstract}

\section{Keywords}

Dabus Sub-Basin, Scenarios, Surface Water Potential, Water Demand, WEAP

\section{Introduction}

Water is essential to all forms of life on earth including human beings, animals and plants to sustain their life [1]. It is crucial for the wellbeing of mankind and 
it supports all aspects of human activity for living [1]. Furthermore, water plays an irreplaceable role in supporting productive human activities such as agricultural, energy production, industrial, transportation services, fishing, sanitation and tourism [1]. However, its availability, quantity, distribution and quality have been reducing over time as a result of climate change, emerging demand due to population growth and economic development [2]. As a result, a significant number of countries in the world are becoming water-stressed. To solve the scarcity problem different countries of the world are implementing different policies to boost the management system of the available water resources [2].

The careful estimation of surface water potential of a river basin is very essential for the future development of any kind of water-related project in countries like Ethiopia [3]. This, in turn, enhances the economic growth of the country by paving the way for utilization of the available potential of water for hydropower, irrigation, and water supply [3]. Planning, managing, designing, constructing, and operating of the water resources project are essential for using the available water resources [3]. Additionally, studying surface water potential and evaluating the demand are important because they provide information to the decision-makers about the river basin on how much water is available and how much is utilizable for different purposes. This will be helpful for available resources allocation and development of water-related projects [3].

The water resources potential assessment needs detailed insights into the hydrological process and its components. Studying hydrological processes for sustainable basin management based on the knowledge of rainfall characteristics and basin properties is important [4]. However, water resources projects are designed for meeting the current and future water demands, and also it is mandatory to sustain the ecology and environment of the sub-basin by continuously releasing a flow with the minimum flow requirement which balances the variations of the weather condition in the sub-basin [4].

Both the complexity of allocation of water and the increasing of the pressure on water resources (increase in demand and change in climate) has motivated the revision of water allocation goals in many countries around the world [5]. This, depict that for effective and improved water management having an overview of water availability and reliability together with consideration of the key principles of the equity [6], efficiency and sustainability are vital. This has forced scientists and planners to formulate proper water allocation approaches and related policies in Integrated Water Resources and Management (IWRM) [6]. A clear understanding of the water resources at a basin level is important to meet the increasing water demand of the world's population and to achieve secure and sustainable water use in the future [6]. Therefore the main objective of the study is: 1) To assess the surface water potential of the Dabus sub-basin; 2) To assess the demand of water for different uses under different scenarios in the sub-basin; 3) To check whether the available water meets the demand of water in the sub-basin under different scenarios. 


\section{Materials and Method}

In order to achieve the above stated objective the following methodology has been employed.

\subsection{Location of Study Area}

The Dabus sub-basin is a north-flowing tributary of the Blue Nile river in southwestern Ethiopia; located at range of latitude of $9^{\circ} 00^{\prime} 00^{\prime \prime} \mathrm{N}$ to $10^{\circ} 45^{\prime} 00^{\prime \prime} \mathrm{N}$, and longitude of $34^{\circ} 30^{\prime} 00^{\prime \prime} \mathrm{E}$ to $35^{\circ} 40^{\prime} 00^{\prime \prime} \mathrm{E}$ and it joins its parent stream at $10^{\circ} 36^{\prime} 38^{\prime \prime} \mathrm{N}$ and $35^{\circ} 08^{\prime} 58^{\prime \prime} \mathrm{E}$. The Dabus sub-basin has a drainage area of about 14,367.74 square kilometers [7]. The altitude in the sub-basin ranges between 485 and $3150 \mathrm{~m}$ above mean sea level (Masl) the high land in the eastern part of the sub-basin are higher in altitude, greater than 1600 Masl up to 3150 Masl [8] The lowland in the northern parts of the sub-basin have lower altitude less than 800 Masl [8]. Figure 1 shows the location of Dabus sub-basin.

\subsection{Materials}

For this research the watershed is delineated automatically using WEAP and the software's employed include Arc GIS 4.0, CROPWAT 8.0, CLIMWAT 2.0, USGS earth explore, Microsoft word and excel. All the latest hydro-metrological data (precipitation, evapotranspiration, and $P_{e f f}$ ) and the latest land-use data from United States Geographic System (USGS) earth explorer Landsat 8 version were used together with the corresponding Kc value for surface water potential estimation. The dominant land-use was found to be bare land, vegetation, forest and water-bodies. For the demand side annual activity level, annual water use rate, monthly variation and consumption rate for each demand type including (domestic, livestock, agricultural, Environmental Flow Requirement (EFR), and industrial) was used as input in evaluating the annual demands.

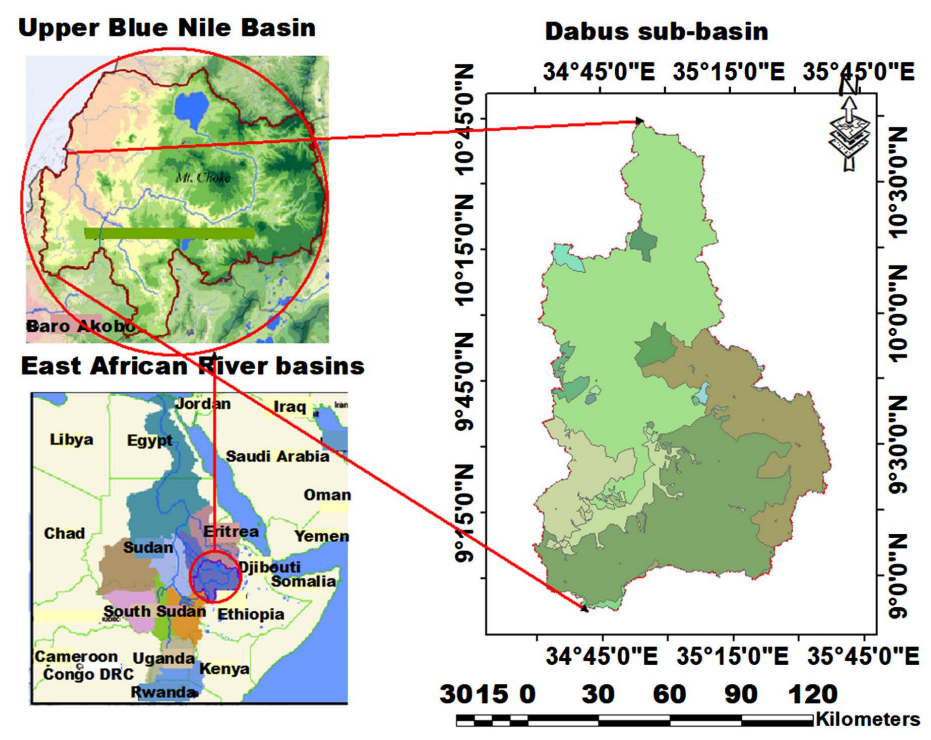

Figure 1. The location of Dabus sub-basin in the upper Blue Nile basin. 


\section{Methods}

The methodology followed in this research is data collection, hydro-metrological data analysis, modeling the watershed, surface water potential assessment and demand evaluation using the model WEAP.

\subsubsection{Hydro-Metrological Data Processing \\ Data screening}

The precipitation data has been checked for its homogeneity by using the homogeneity test [9]. The non-dimensional parameter $P_{i}$ is given by:

$$
P_{i}=\frac{P_{i, a v}}{P_{a v}} * 100 \quad[9]
$$

where, $P_{p}$, represents precipitation for the month $i$ and it is non-dimensional value, $P_{i, a v}$ is over year's averaged monthly precipitation of the station $i . P_{a v}$ is over year's averaged yearly precipitation of the station.

The consistency of the precipitation data is checked using double mass curve method [10].

$$
P_{c x}=P_{x} * \frac{M_{c}}{M_{a}}[10]
$$

where: $P_{c x}$ is corrected precipitation at any time, $P_{x}$ is originally recorded precipitation at any time, $M_{c}$ is corrected slope of the double mass curve and $M_{a}$ is original slope of the double mass curve.

1) Missing data completion

A number of methods have been proposed to estimate missing rainfall data [9]. Normal ratio method is used for filling missing precipitation data.

$$
P_{m}=\frac{1}{n}\left\{\sum_{k=0}^{n}\left(\frac{N_{m}}{N_{i}}\right) P_{i}\right\}
$$

where, $N_{m}$ : Average annual rainfall for the gauge in which data are missing, $N_{i}$ : Average annual rainfall at gauge $i$. and arithmetic mean method was used for filling the stream flow data.

\section{2) Areal rainfall estimation}

The selected rainfall stations need to be uniformly distributed in order to represent the entire sub-basin, as there might be different geological and hydrological features in different parts of the sub-basin. Thiessen polygon method was used for checking the uniformity of the rainfall station distribution over the entire sub-basin [9]. As the result shows the stations are uniformly distributed over the sub-basin. The location of the rainfall stations in the sub-basin is shown in Figure 2.

\subsubsection{WEAP Application}

The Water Evaluation and Planning software is used in this study. WEAP model basically calculates a mass balance flow sequentially down a river system, making allowance for abstractions and inflows [11]. The elements in the model help to 


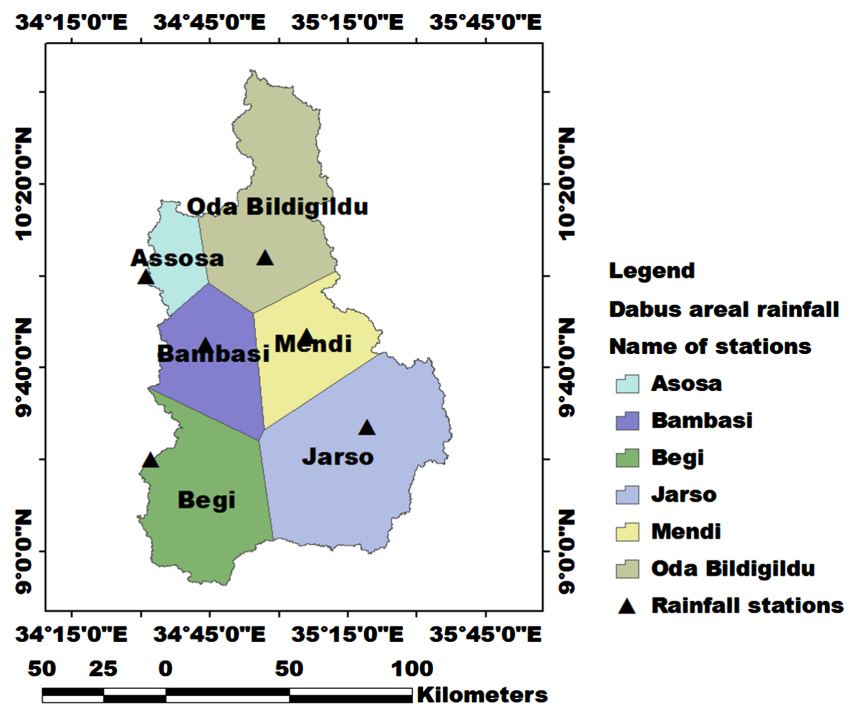

Figure 2. The location of stations in the sub-basin.

characterize the water demand-supply system and their spatial relationships [11].

The function of the model is not to describe the hydrological process of the sub-basin accurately, but to be able to simulate the surface water resources of the study area within the available data and using a small number of parameters [11].

Five different sets of "views" are structured onto the working area to form the WEAP model complete: Schematic, Data, Results, Scenario Explorer and Notes [10]. These views are listed on the left side of the screen as graphical icons. Schematic is GIS tool for configuring the system through dragging and dropping to create and position, helps to add other standards in the forms of vector or raster GIS image as background layers. It is an associate access to data and results for any given node. Data view helps to build the model. It produces variables and relationships, enter assumptions and projections using mathematical expressions, and immediately links to excel. Notes help to document data and assumptions. Results view helps to display detailed model outputs in the form of charts, tables and maps. Scenario Explorer is a higher level view of data and results. The slider moves to change the value of connected scenario data variable and WEAP recalculates so that the impact on user-selected key results are displayed [11].

The main menu located at the top provides access to the basic functions of the programs. The current area name, current view, licensing information and other status information are presented in the status bar at the bottom of the screen. The layout of the remaining screen depends on the selected view [11].

From the five methods presented in WEAP model and listed below the rainfall-runoff method is used for this research.

1) Irrigation Demands only method;

2) The Rainfall-Runoff method;

3) The soil moisture method; 
4) The MABIA method; and

5) The plant growth method.

Irrigation Demands approach calculates the potential evapotranspiration in the catchment by using crop coefficient, then irrigation demand is identified to cover the parts of evapotranspiration that are not covered by the rainfall [12]. In this method runoff cannot be simulated and infiltration is not calculated. The Rainfall-Runoff method also uses crop coefficient in evapotranspiration calculation for irrigated and "rain-fed" crops [12]. The remaining portion of rainfall which is not consumed by the evapotranspiration is simulated as surface runoff in the river. Among the five methods the soil moisture method is the most complex one. It represents the soil with two layers and also represents the potential for snow accumulation. It simulates the evapotranspiration in the upper layer by considering rainfall and irrigation on agricultural and non-agricultural land, runoff and shallow interflow in the soil moisture [13]. These methods permit the characterization of land cover and/or soil type impacts to the hydrologic process. In the lower soil layer base flow routing and soil moisture changes are simulated. Considerably this method requires comprehensive data to simulate each process in the system, those kinds of data are not available easily [13].

Steps followed by WEAP for surface water potential assessment and demand evaluation [13].

1) Defining the study area, time frame, system components and configuration.

2) Creating the current account, it is water resources potential of the study area.

3) Creating of the scenarios based on future assumptions and expected increases in the various indicators. This forms the core or the heart of the WEAP model since this allows for possible water resources management processes to be adopted from the results generated from running the model.

4) Evaluating the scenarios about the availability of the water resources for the study area.

Results generated from the creation of scenarios can help the water resources planner in decision making, which is the core of this study.

\subsubsection{Model Calibration}

The term calibration refers to the adjustment of a model parameter such as roughness, hydraulic structure coefficients, etc., in order to make the model produces the observed prototype data at an acceptable range of accuracy [11]. The objective function and subjective criteria are the two general approaches to assess the best fitness of data. The objective function is used in this study. The aim of WEAP model calibration is fitting the simulated data to the observed flow data collected from gauging stations, which involves the quantitative evaluation of hydrologic response of the Dabus sub-basin and its tributaries [11].

The model calibration is attained by using the EF (Nash-Sutcliffe Efficiency) and $\mathrm{R}^{2}$ (coefficient of determination) since the Software (WEAP), has no automatic calibration routine; due to this reason the changes implemented were tested manually by comparing the simulated and observed time series flow [11]. 


\section{Nash and Sutcliffe efficiency criteria}

The objective assessment relies on creating measures of errors using statistical parameters for evaluations of the model. These error methods include mean error (ME), mean square error (MSE) and the model coefficient of efficiency (EF) [14]. The MSE measures the mean square of the errors, which is the difference between the simulated and observed flow values. The EF is used in assessing the predictive power of hydrological models [15]. It is the non-dimensional parameter and scaled version of MSE ranging between 0 and 1, most of the time it gives clearer evaluation of the model results and performances. The efficiency value 1 indicates a perfect match between the observed and simulated discharge whereas, the efficiency value 0 indicates that the model prediction is accurate as the mean of the observed data [16].

$$
\begin{gathered}
E_{Q}=Q_{m}-Q_{o} \\
\mathrm{ME}=\sum_{i=1}^{n}\left(\frac{Q_{m}(i)-Q_{o}(i)}{n}\right)=\sum_{i=1}^{n}\left(\frac{E_{Q}(i)}{n}\right) \quad[10] \\
\mathrm{MSE}=\sum_{i=1}^{n}\left(\frac{Q_{m}(i)-Q_{o}(i)}{n^{2}}\right)=\sum_{i=1}^{n}\left(\frac{E_{Q}(i)}{n^{2}}\right)[10] \\
\mathrm{EF}=\left[1-\frac{\mathrm{MSE}}{S^{2} Q_{o}}\right]
\end{gathered}
$$

where: $E_{Q}=$ Difference between simulated and observed flow, $Q_{o}=$ Observed flow, $Q_{m}=$ Simulated flow, $\mathrm{ME}=$ Mean Error, $\mathrm{MSE}=$ Mean Squared Error, and $\mathrm{EF}=$ Model Efficiency Coefficient, and $S=$ Variance.

\section{Coefficient of determination, $R^{2}$}

The coefficient of determination is $R^{2}$ is defined as the squared value of coefficient of correlation of the simulated and observed streamflow. Coefficient of determination is also used for this research for calibration. It is estimated using the following formulae [11].

$$
R^{2}=\frac{\left[\sum_{i=1}^{n}\left(Q_{o}-\bar{Q}_{s}\right)\left(Q_{o}-\bar{Q}_{o}\right)\right]^{2}}{\left[\sum_{i=1}^{n}\left(Q_{s}-\bar{Q}_{s}\right)\right]^{2}\left[\sum_{i=1}^{n}\left(Q_{o}-\bar{Q}_{o}\right)\right]^{2}}
$$

where $Q_{o}=$ observed flow,

$Q_{s}=$ Simulated flow,

$\bar{Q}_{o}=$ Mean observed flow,

$\bar{Q}_{\mathrm{s}}=$ Mean simulated flow.

\section{Result and Discussion}

\subsection{Surface Water Availability}

The mean monthly runoff value of the sub-basin is shown in Table 1 for different catchments of the sub-basin. 
Table 1. Monthly average runoff in Million Cubic Meter (MCM) in Dabus sub-basin.

\begin{tabular}{cccccccccccccc}
\hline & Jan & Feb & Mar & Apr & May & Jun & Jul & Aug & Sep & Oct & Nov & Dec & Sum \\
\hline C-1 & 1 & 0 & 5 & 47 & 154 & 114 & 178 & 292 & 120 & 47 & 4 & 3 & 964 \\
C-2 & 0 & 1 & 3 & 19 & 53 & 363 & 631 & 812 & 532 & 163 & 17 & 2 & 2597 \\
C-3 & 1 & 1 & 4 & 25 & 71 & 255 & 468 & 373 & 168 & 46 & 7 & 2 & 1421 \\
C-4 & 2 & 3 & 5 & 28 & 123 & 254 & 211 & 206 & 171 & 57 & 16 & 12 & 1087 \\
C-5 & 0 & 0 & 1 & 4 & 13 & 44 & 39 & 49 & 26 & 17 & 2 & 1 & 196 \\
C-6 & 0 & 0 & 0 & 4 & 13 & 47 & 64 & 82 & 37 & 22 & 2 & 1 & 271 \\
Sum & & & & & & & & & & & & & 6536 \\
\hline
\end{tabular}

Note: C1, C2, C3, C4, C5 and C6 are catchment 1, catchment 2, catchment 3, catchment 4, catchment 5 and catchment 6 respectively.

\section{Model Performance}

The result from the model performance tested by using the two methods namely Nash and Sutcliffe criteria (EF) and coefficient of determination $\left(R^{2}\right)$ is presented in Table 2.

Both the parameters used for calibration showed good fitness of the observed and simulated streamflow data.

\section{Water Balance}

As a result from the model indicates from the total rainfall of 14,987 MCM $6536 \mathrm{MCM}$ (which is 43 percent of the total rainfall) is contributing to the surface runoff and the remaining 57 percent to evapotranspiration; the overall water balance is shown in Figure 3. This means the water that is consumed by vegetation and evaporation is considerably high.

The figure indicates the amount of surface runoff and evapotranspiration generated from the total rainfall.

\subsection{Water Demand in the Sub-Basin}

\subsubsection{Water Demand Model in WEAP}

WEAP examines water demand in an area based on disintegrated end-use approach [17]. By applying WEAP21 one can use economic, demographic and water-use information to develop scenarios that analyze how total and disaggregated consumption of water grow over time in all sectors of the economy [17]. Calculation of demand for domestic, livestock and agriculture entities are based on a disintegrated accounting for several measures of social and economic activity such as population served, livestock population size and area of land irrigated [17]. In this study 10 percent of the domestic water demand is assigned for industrial demand, by taking into consideration the future growth of industry in the area. Regardless at present time there is small industrial activity (only one site of gold mining) in the sub-basin. Environmental flow requirements (EFR) are also considered in this study to sustain the ecosystem of the area by taking 10 percent of the total annual flow. Standard Water Use Method was selected, in which the modeler determines each water user type (activity) for each end-user and inputs the correct annual water use rate for each activity [17]. 


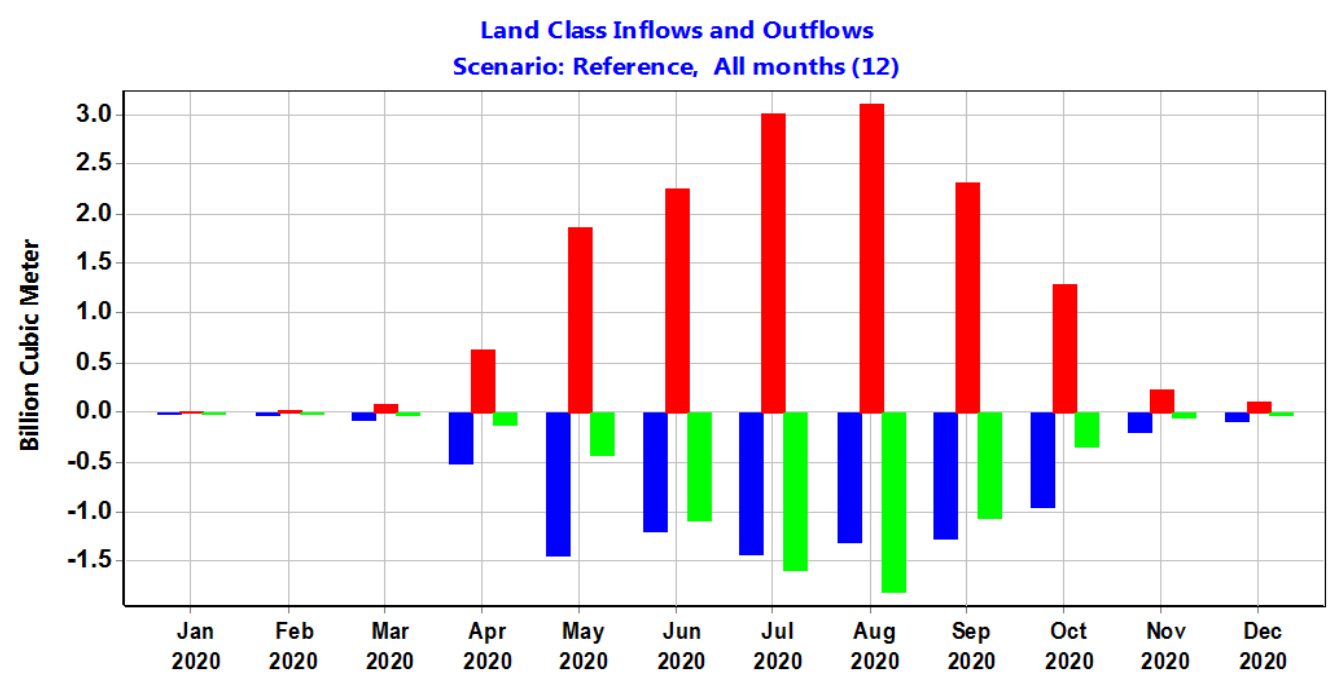

Figure 3. Water balance of the study sub-basin.

Table 2.Statistical parameters for calibrations.

\begin{tabular}{cccccc}
\hline & \multicolumn{3}{c}{ Statistical parameters } & $\begin{array}{r}\text { Coefficient of } \\
\text { determination }\end{array}$ \\
\cline { 2 - 6 } Gauging stations & $\begin{array}{c}\text { Mean of } Q_{o} \\
\mathrm{Mm}^{3}(\mathrm{ME})\end{array}$ & $\begin{array}{c}\text { Standard } \\
\text { deviation } \\
\text { (STDEVA) }\end{array}$ & $\begin{array}{c}\text { MSE } \\
(\mathrm{Mm})^{6}\end{array}$ & EF & $R^{2}$ \\
\hline Dabus near Asosa (c-1) & 49.44 & 90.68 & 4.12 & 0.95 & 0.95 \\
Sechi near Mendi (c-2) & 16.29 & 33.77 & 1.35 & 0.97 & 0.97 \\
\hline
\end{tabular}

\section{Current account year (Base year: 2020)}

The current account year is the base from which all the other scenarios developed from.

\section{Types of demand considered}

1) Domestic demand

2) Industrial demand

3) Irrigation demand

4) Livestock demand

5) Environmental flow requirement (EFR) demand

The total water demand for the year 2020 is 867 MCM and it is percentage to each demand sector is shown in Figure 4.

\subsubsection{Scenario Development}

A scenario is a probable description of how the future may emerge based on articulate and internally consistent set of assumptions about key interactions and driving forces in the hydrologic processes [18].

In order to contain future water demand sophistication four different scenarios have been developed under three different time horizons which are listed as follows: 


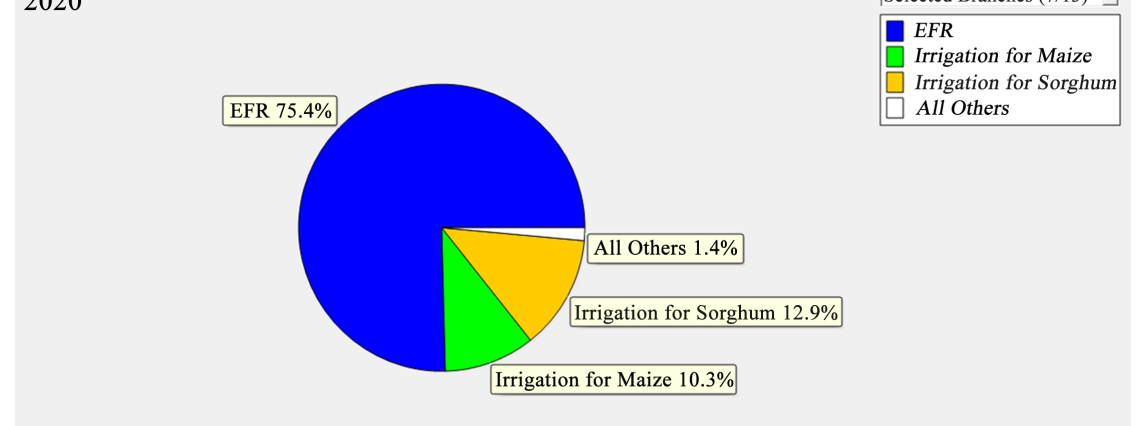

rrigation for Maize

Irrigation for Sorghum All Others

Figure 4. Percentage of overall water demand for the year 2020 (current account year).

\section{1) Scenario 1: Reference scenario (2021-2050)}

Under this scenario the demands are met with 100 percent coverage and the largest percentage of demand comes from the environmental flow requirement and lowest being the domestic water demand (urban and rural) as shown in Figure 5. This implies for this scenario if situation indicated prevailed the surface water from the sub-basin is sufficient, so no additional source of water is required.

2) Scenario 2: Domestic water demand change due to population growth rate

Under this scenario as it is indicated in Figure 6 the domestic water demand is analyzed for the three different growth rate probability: high, low, and medium and all the demands met with 100 percent coverage. This shows if one of the three conditions prevails in the future, the surface water from the sub-basin is sufficient and no need for additional source of water for supply.

\section{3) Scenario 3: Irrigation demand projection}

Under this scenario the irrigation area is increased and as the result indicates there is unmet demand under irrigation projection scenario for the months of Apr and May. The unmet demand is presented in Figure 7.

\section{4) Scenario 4: Increased water demand scenario}

Under this forth scenario the domestic demand i.e. both for rural and urban population, the demand has been increased regardless of the surface water potential. However, the water resources potential in the sub-basin met the demand with 100 percent coverage, so if the mentioned scenario prevailed there is no need for considering any additional sources of water Figure 8 shows the coverage of the demand under this scenario.

\section{Discussion}

The four scenarios are developed and evaluated based on different parameters and assumption for each of them. The three scenarios namely reference, domestic water demand change, and increased water demands are met within the available water resources for the three scenarios, but one scenario (Irrigation water demand projection) has unmet demand in the months of April and May. 


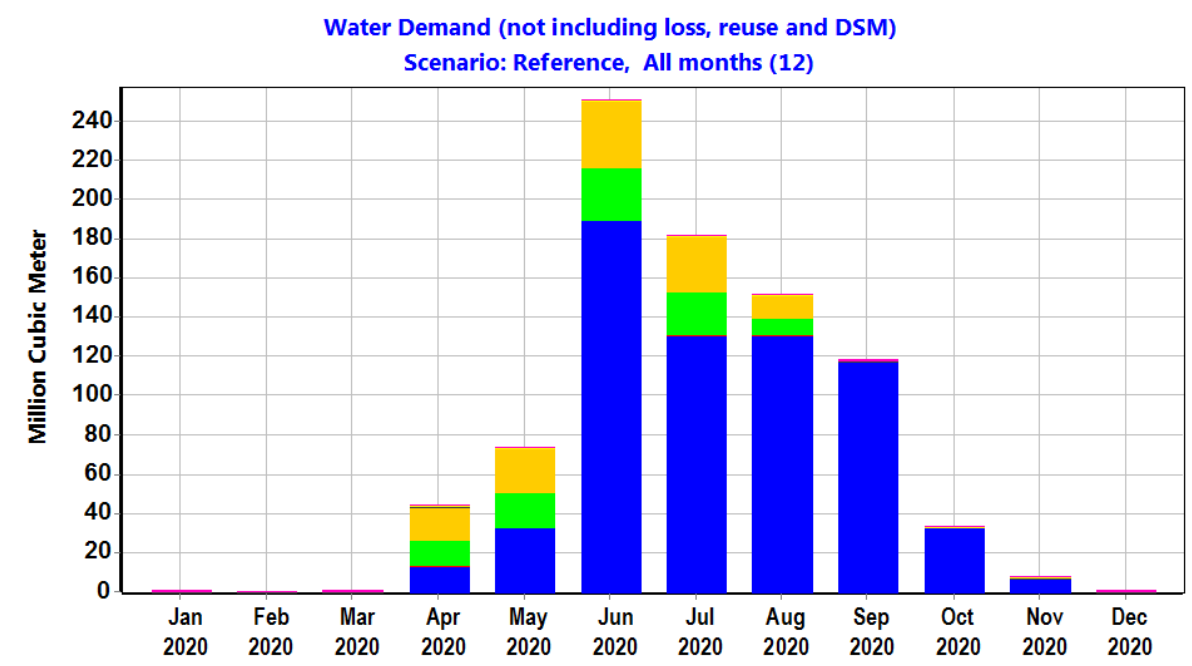

\begin{tabular}{|l|}
\hline EFR \\
Industrial \\
Irrigation for Maize \\
Irrigation for Sorghum \\
Livestock \\
Rural Demand \\
Urban Demand
\end{tabular}

Figure 5. Reference scenario average monthly coverage of sub-basin.

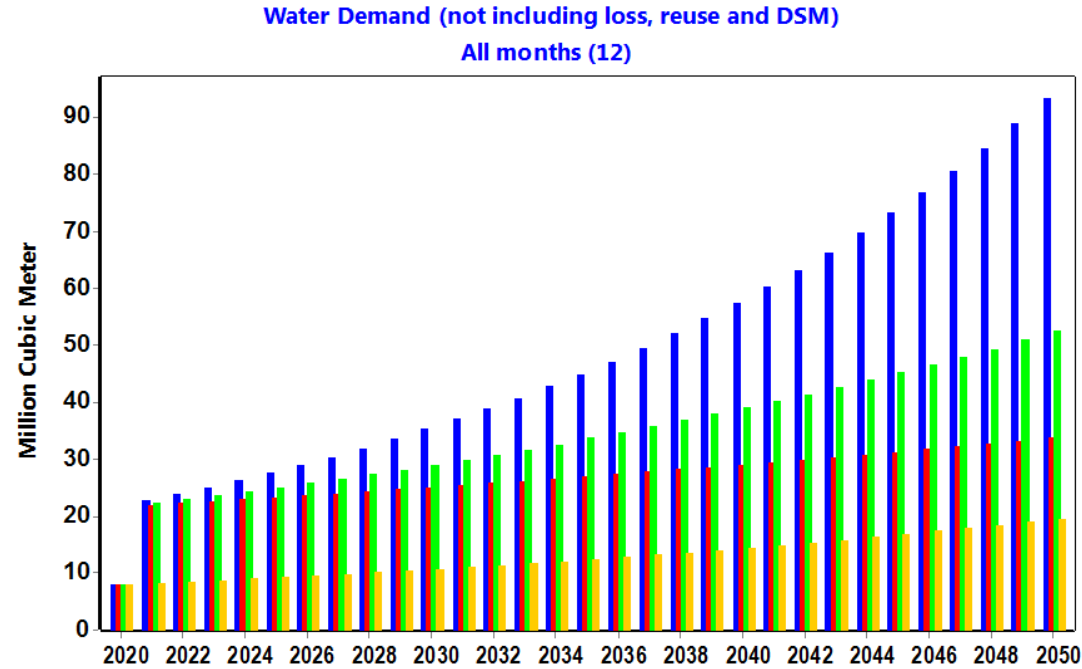

Figure 6. Total domestic water demand under different population growth rate.

Unmet Demand

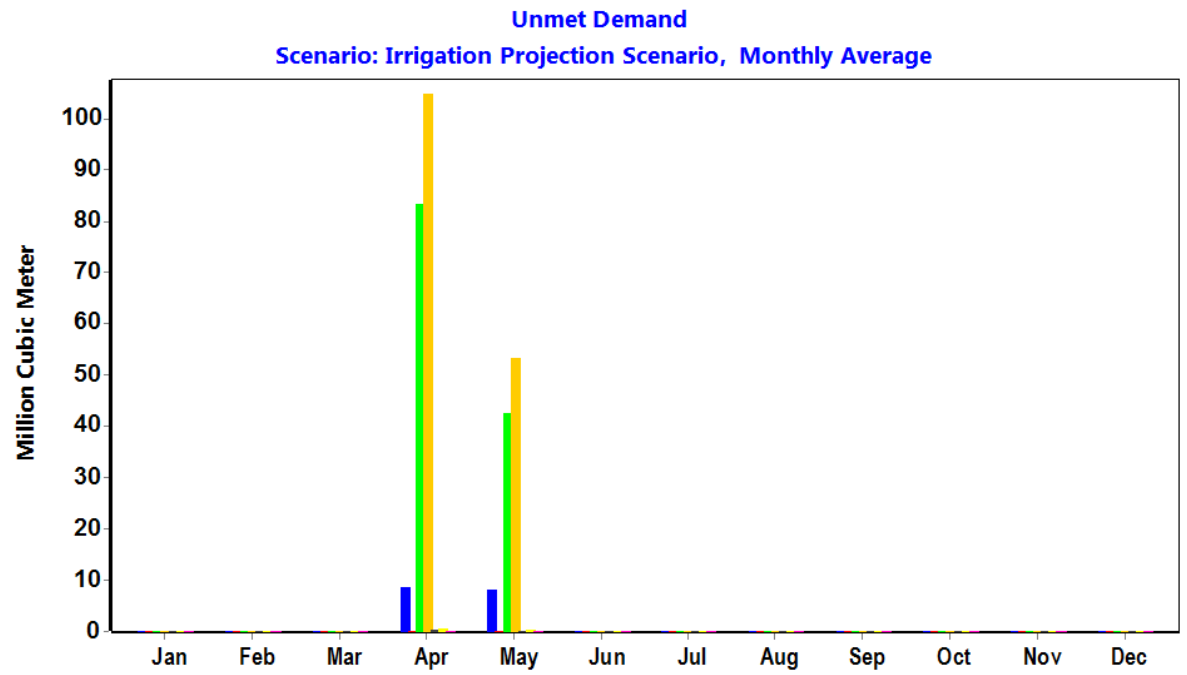

Figure 7. Water demand for irrigation projection scenario. 


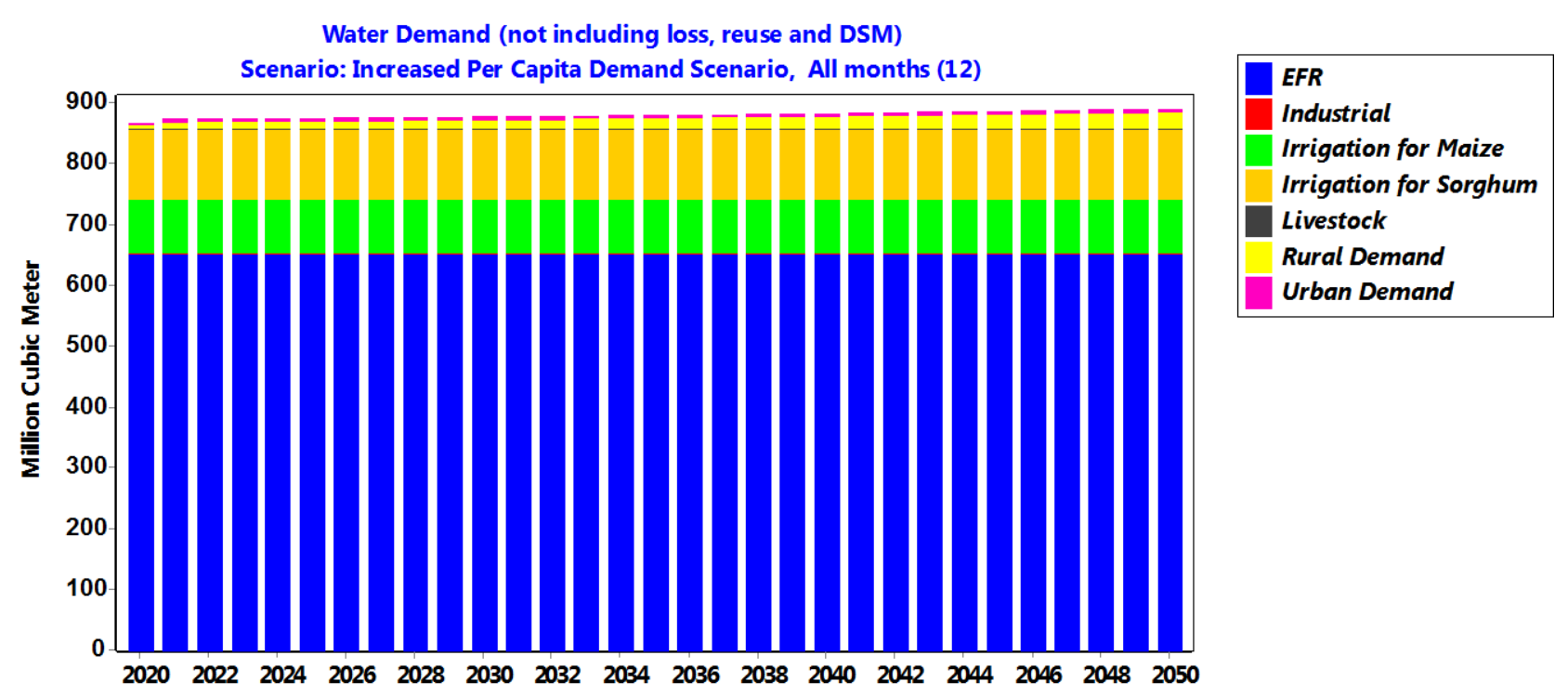

Figure 8. Water demand coverage under Scenario 4.

This clearly shows if such scenario prevails in the future additional sources of water are required.

\section{Conclusions}

The main aim of the study was to assess the surface water potential and evaluate current and future water demand with the available data. WEAP model was used to perform the analysis for the water resources availability, demand evaluation, and water management scenarios. It should be known that performing such analysis and simulation is difficult when the available data is limited. The application of Arc GIS software provides a powerful platform to perform the analysis of land use/cover, soil data and Digital Elevation Model (DEM) layers and related topographic attributes which help to capture the complexity of the sub-basin and incorporate them with WEAP.

The model was able to simulate the sub-basin water availability and water management scenario. As the calibration and validation of the simulated results, EF indicates the modelled result was good, implying the model was well adapted to the catchment. The r-squared $\left(\mathrm{R}^{2}\right)$ values show that the model performed well. Regardless the model can perform and may come up with better results if data both from the demand and supply side were full and sufficient as per the requirement of the model input. Even though, the demands in the sub-basin are met for most of the scenarios including the reference scenario, there is also unmet demand for one scenario namely irrigation demand projection some months of the year, so if such scenario may happen in the future another supply option has to be considered.

\section{Acknowledgements}

We would like to thank Wollega University Hydraulics and Water Resources 
Engineering staff members for providing us with conducive working environments whenever we needed.

We need to express our appreciation to institutions and offices namely ministry of water, irrigation and electricity, Ethiopian central statistical agency, Assosa Meteorological bureau and Abay authority Nekemte branch for their positive support on data collection and organizing.

\section{Conflicts of Interest}

The authors declare no conflicts of interest regarding the publication of this paper.

\section{References}

[1] UNEP (United Nations Environment Programme) (2009) Water Security and Ecosystem Services. The Critical Connection. A Contribution to the United Nations World Water. United Nations Environment Programme, Unpublished.

[2] Nata, T. (2006) Surface Waters Potential of the Hantebet Basin, Tigray, Northern Ethiopia. Agricultural Engineering International, 8, 1-31.

[3] Alkasim, M. (2016) Assessment and Evaluation of Surface Water Potential and Demands in Baro-Akobo River Basin, Ethiopia. Masters's Thesis, Addis Ababa University, Addis Ababa.

[4] Abushandi (2011) Rainfall-Runoff Modelling in Arid Areas. PhD Thesis, Faculty for Geosciences, Geotechnique and Mining of the Technische Universität Bergakademie Freiberg, Unpublished.

[5] Roa-Garcia (2014) Equity, Efficiency and Sustainability in Water Allocation in the Andes: Trade-Offs in a Full World. Water Alternatives, 7, 298-319.

[6] UN.ESCAP (United Nations Economic and Social Commission for Asia and the Pacific) (2000) Principles and Practices of Water Allocation among Water-Use Sectors. United Nations, New York.

[7] Aster Denekew, Y. and Seleshi Bekele, A. (2009) Characterization and Atlas of the Blue Nile Basin and Its Sub Basin. http://hdl.handle.net/10568/38169

[8] MoWE (Minister of Water and Energy) (2015) Engineering Services for Hydropower Cascade. Dabus Hydropower (Ethiopia), Unpublished.

[9] Engdaw, K. (2015) Assessment on Surface Water Potential and Demands of Wabishebele Basin in Ethiopia. Master's Thesis, Addis Ababa University, Addis Ababa.

[10] Vogel, R.M., Sieber, J., Archfield, S.A., Smith, M.P., Apse, C.D. and Huber-Lee, A. (2007) Relations among Storage, Yield, and Instream Flow. Water Resources Research, 43, W05403. https://doi.org/10.1029/2006WR005226

[11] Abebe, S. (2016) Application of Water Evaluation and Allocation Planning (WEAP) Model to Assess Future Water Demands and Water Balance of the Caleoden River Basin. Master's Dissertation, Central University of Technology, Free State.

[12] SEI (Stockholm Environment Institute) (2016) Water Evaluation and Planning System: Tutorial. Stockholm Environment Institute, Stockholm.

[13] Levite, H., Sally, H. and Cour, J. (2003) Testing Water Demand Management Scenarios in a Water-Stressed Basin in South Africa: Application of the WEAP Model. Physics and Chemistry of the Earth, Parts $A / B / C$, 28, 779-786. https://doi.org/10.1016/j.pce.2003.08.025 
[14] Ahmed, A., Massoud, T. and Hosein, A. (2007) Water Resources Management Scenario Analysis in the Karkheh River Basin Iran, Using the WEAP Model. Hydrological Science and Technology, 23, 1-4.

https://www.researchgate.net/publication/267697184

[15] Krause, P., Boyle, D.P. and Base, F. (2005) Comparison of Different Efficiency Criteria for Hydrological Assessment. Advances in Geosciences, 5, 89-97. https://doi.org/10.5194/adgeo-5-89-2005

[16] Tesfaye, E. (2014) Proceedings of the 4th National Conference on Environment and Development. Dilla, Ethiopia, Unpublished.

[17] Mugastsia, E.A. (2010) Simulation and Scenario Analysis of Water Resources Management in Perkerra Catchment Using Weap Model. Master's Thesis, Moi Univesity, Kesses.

[18] Arranze, R. and McCartney, M. (2007) Application of the Water Evaluation and Planning (WEAP) Model to Assess Future Water Demands and Resources in the Olifantscatchment, South Africa. IWMI Working Paper No. 116, International Water Management Institute, Kedar Park Society, 103 p.

\section{Abbreviations}

BCM: Billion Cubic Meter

DEM: Digital Elevation Model

E: East

EFR: Environmental Flow Requirement

EF: Nash-Sutcliffe simulation Efficiency

GIS: Geographical Information System

IWRM: Integrated Water Resources Management

ME: Mean Error

MSE: Mean Square Error

MOWE: Minister of Water and Energy

SEI: Stockholm Environment Institute

WEAP: Water Evaluation and Planning

UNEP: United Nation Environment Program

UNESCA: United Nation Economic and Social Commission for Asia 